\title{
Regional cerebral blood flow correlates of visuospatial tasks in Alzheimer's disease
}

\author{
WILLIAM J. TIPPETT ${ }^{1-3}$ AND SANDRA E. BLACK ${ }^{1-5}$ \\ ${ }^{1}$ L.C. Campbell Cognitive Neurology Research Unit, Toronto, Ontario, Canada \\ ${ }^{2}$ Heart and Stroke Foundation Centre for Stroke Recovery, Toronto, Ontario, Canada \\ ${ }^{3}$ Sunnybrook Health Sciences Centre Toronto, Ontario, Canada \\ ${ }^{4}$ Division of Neurology, Department of Medicine, Toronto, Ontario, Canada \\ ${ }^{5}$ University of Toronto, Toronto, Ontario, Canada
}

(Received January 15, 2008; Final Revision June 27, 2008; Accepted July 1, 2008)

\begin{abstract}
This study investigated the role of visuospatial tasks in identifying cognitive decline in patients with Alzheimer's disease (AD), by correlating neuropsychological performance with cerebral perfusion measures. There were 157 participants: 29 neurologically healthy controls (age: $70.3 \pm 6.6$, MMSE $\geq 27$ ), 86 patients with mild AD (age: $69.18 \pm 8.28$, MMSE $\geq 21$ ) and 42 patients moderate/severe AD (age: $68.86 \pm 10.69$, MMSE $8-20$ ). Single Photon Emission Computerized Tomography (SPECT) was used to derive regional perfusion ratios, and correlated using partial least squares (PLS) with neuropsychological test scores from the Benton Line Orientation (BLO) and the Rey-Osterrieth Complex Figure (RO). Cross-sectional analysis demonstrated that mean scores differed in accordance with disease status: control group (BLO 25.5, RO 33.3); mild AD (BLO 20.1, RO 25.5); moderate/severe AD (BLO 10.7, RO 16). Correlations were observed between BLO/RO and right parietal SPECT regions in the $\mathrm{AD}$ groups. Visuospatial performance, often undersampled in cognitive batteries for AD, is clearly impaired even in mild $\mathrm{AD}$ and correlates with functional deficits as indexed by cerebral perfusion ratios on SPECT implicating right hemisphere circuits. Furthermore, PLS reveals that usual spatial tasks probe a distributed brain network in both hemispheres including many areas targeted by early AD pathology. (JINS, 2008, 14, 1034-1045.)
\end{abstract}

Keywords: Cerebral perfusion, Partial least squares, SPECT, Pathology, Neuropsychology, Parietal lobe

\section{INTRODUCTION}

Although progressive memory and imaging deficits have been the predominant focus in both clinical and clinical trial assessments in Alzheimer's disease (AD; Loewenstein et al., 2006; Mandzia et al., 2002; Mohs \& Cohen, 1988; Salmon et al., 2008), other cognitive deficits may assist in the detection and characterization of patients with AD. Research suggests that the parietal lobe, more specifically the posterior parietal cortex, is essential for directing ongoing movements (Buneo \& Andersen, 2006) as well as for conducting visually-guided reaching and grasping activities (Goodale, 1993). Historically, parietal deficits have been linked to disruptions in visuomotor planning and movement (Andersen \& Buneo, 2003; Snyder et al., 1997), such

Correspondence and reprint requests to: B.J. Tippett, Cognitive Neurology Research Unit, Sunnybrook Health Sciences Centre, 2075 Bayview Avenue, Room A419, Toronto, Ontario M4N 3M5, Canada. E-mail: bj.tippett@ sunnybrook.ca as updating the spatial location of targets (Buneo \& Andersen, 2006; Snyder et al., 1997) and programming coordinated arm and eye movements (Duhamel et al., 1992; Grea et al., 2002; Oyachi \& Ohtsuka, 1995). Visuospatial and visuomotor ability are typically under-used in cognitive batteries for AD but have the potential to assist in diagnosing and monitoring of AD (Ghilardi et al., 1999; Tippett \& Sergio, 2006). The parietal region is an area known to be vulnerable to AD pathology as it progresses from the limbic to the neocortical stage (Braak \& Braak, 1991) and dysfunction in this region correlates with several visuomotor difficulties (Andersen \& Buneo, 2003; Braak \& Braak, 1991; Buneo et al., 2002; Nagahama et al., 2003).

Positron Emission Tomography (PET) and Single Positron Emission Computed Tomography (SPECT) are functional imaging techniques that can produce three dimensional maps of resting state brain activity based on glucose metabolism or blood flow, which can be helpful in inferring the presence of AD pathology (Alexander et al., 2002; Buchert 
et al., 2005; Cutler, 1988; Ishii et al., 2006; McGeer et al., 1986; Silverman et al., 2001; Silverman, 2004; von Broczyskowski et al., 2006)

Psychophysical research has demonstrated that reductions in visuomotor ability attributed to parietal dysfunction may be useful in detecting not only the presence of $\mathrm{AD}$, but also in tracking its progression (Elble \& Leffler, 2000; Ghilardi et al., 1999; Kluger et al., 1997; Ott et al., 1995; Tippett \& Sergio, 2006). Decline in perfusion rates within regions such as the parietal lobe, can occur in the early stages of $\mathrm{AD}$.

Finding sensitive, valid noninvasive procedures to detect early AD has become a major goal of AD research. To index disease, functional deficits on neuropsychological tests should correlate with regional dysfunction on neuroimaging (Nobili et al., 2005). SPECT has been widely used to identify regional cerebral perfusion deficits indicating the presence of $\mathrm{AD}$ and other dementias (Bonte et al., 2004; Mito et al., 2005) because it is relatively inexpensive and more widely available compared with PET, though it has lower sensitivity and spatial resolution (Bartenstein et al., 1997; Desgranges et al., 1998; Elgh et al., 2002; Lampl et al., 2003; Meguro et al., 2001; Yamaguchi et al., 1997).

Traditionally, the focus for examining brain-behavior relationships in $\mathrm{AD}$ has been in relation to memory or language performance. Previous in vivo research designs examining pathological decline in relation to cognitive dysfunction, such as memory and language impairments, however, have demonstrated some shortcomings. For example, severity of the illness is often not controlled for, and this can be problematic because cognitive scores and perfusion ratios can vary with disease stage (Kogure et al., 2000; Matsuda et al., 2002; Nobili et al., 2005). Most studies have focused on anatomical regions associated with memory/language tasks using a region of interest approach; for example, correlations have been sought between the perfusion ratios in a single region, such as the medial temporal lobe with exclusion of other cerebral areas (Lampl et al., 2003; Nobili et al., 2001; Rodriguez et al., 2005). This exclusionary approach, although logical in design as it seeks specific functional correlations, does not probe involvement of other regions, limiting insight into brain connectivity. The relationship between regional blood flow and cognitive performance in individuals with AD particularly for visuospatial and visuomotor performance has not been adequately evaluated, being limited by absence of control groups or small sample sizes (Arbizu et al., 1999; Moren et al., 2005; Nobili et al., 2001, 2005; Starkstein et al., 1996).

\section{Standardized Visuospatial Tasks}

Neuropsychological testing procedures are often used as an index of AD pathology. The current study evaluated two different visuospatial testing procedures in correlation with standardized SPECT data. The two visuospatial tasks selected were: Benton Judgement of Line Orientation (BLO) task and the Rey-Osterrieth complex figure test (RO). BLO is considered to probe "pure" visuospatial ability as it has no visuoconstructive requirements (Benton, 1994). This task has been shown to correlate primarily with right parietal lobe damage (Benton, 1994; Kolb \& Wishaw, 1996) and activation (Herrmann et al., 2005). Successful completion of the Rey-Osterrieth copying task is thought to engage a parietal-frontal network (Kang et al., 2003) related to both spatial analysis and frontal executive processes (Sowell et al., 2001; Temple et al., 2006) as well as temporal regions mediating visual memory (Beebe et al., 2004; Kasai et al., 2006; Stern \& Stern, 1985; Watanabe et al., 2005).

\section{Imaging Correlates of Visuospatial Tasks}

One previous study in $\mathrm{AD}$ patients showed a correlation between shifts in attention to spatial locations and superior right parietal hypoperfusion on SPECT (Buck et al., 1997). As well, functional studies have suggested that recruitment of ventral visual pathway can be used to support visuospatial processing (Prvulovic et al., 2002).

There have been limited functional imaging studies in reference to our chosen visuospatial measures. What has been observed is that BLO performance correlates with increased blood flow (33Xe inhalation $\mathrm{rCBF}$ ) bilaterally within the posterior brain regions (Hannay et al., 1987). Functional MRI (fMRI) research has shown that bilateral superior parietal lobe activation can be observed on a modified BLO task with a more dominant role attributed to the right parietal region. Rey-Osterrieth Complex Figure as a visuospatial task has shown a positive correlation to reduced visuospatial performance in relation to the presence of $\mathrm{AD}$ (Larumbe, 1997; Tei et al., 1997) as well as having a discriminating ability for the presence of early stage AD (Fujimori et al., 1998). Reductions in grey matter in the inferior temporal gyrus correlated with reductions in RO performance (Boxer et al., 2003a).

In addition, lesion data showed that parietal damage to either side is associated with deficits in task performance on BLO but more severe deficits are seen with right-sided damage ( $\mathrm{Ng}$ et al., 2000). Researchers very early on had linked deficits in generating effective visuospatial responses (e.g., manual tacking tasks, line bisection ) to focal damage within the posterior right hemisphere (Bisiach et al., 1986; Levin \& Benton, 1976).

SPECT and PET studies that have shown topographically characteristic reductions in blood flow particularly in the temporal and parietal regions can occur as a result of AD pathology (Foster et al., 1983, 1984; Hirao et al., 2005; Jagust et al., 1997). Hence, impaired BLO performance would be expected.

To ensure a complete evaluation, both a top-down Regions of Interest (ROIs) approach and bottom-up Partial Least Squares (PLS) analysis were performed. The ROI procedure was used to examine critical areas for visuospatial/ visuomotor production, that is, the parietal areas, which as previously noted, are essential for conducting these transformations (Boxer et al., 2003b; Chung et al., 2005; Nobili 
et al., 2005; Rodriguez et al., 2005; Tippett \& Sergio, 2006). In addition, temporal (as noted above) and frontal regions were also evaluated to control for performance reductions which may be a result of overall dementia-related degeneration. However, specific correlation of visuospatial and visuomotor test performance with perfusion ratios on SPECT in the parietal regions in age matched controls and mild and moderate AD was the primary focus of the investigation. Furthermore, the bottom-up approach of the PLS analysis was included to address the issue of specificity, without prior hypothesis. The combined top-down and bottom-up assessment allowed both a hypothesis-driven and unbiased analysis of the brain-behavior relationships for visuomotor/ visuospatial function in $\mathrm{AD}$.

\section{METHODS}

\section{Participants}

Subjects were part of the Sunnybrook Dementia Study, recruited from the Cognitive Neurology clinic at Sunnybrook Health Sciences Centre, a University of Toronto academic healthcare institution. All participants were fluent in English and had adequate visual and auditory acuity to complete neuropsychological testing. A total of 157 participants were divided into three groups: 29 control subjects (MMSE $\geq 27$ ), 86 mild patients $(\mathrm{MMSE} \geq 21$ ) and 42 moderate/severe patients (MMSE 8-20) (see Table 1). The MMSE is widely used in clinical practices and similar cut-offs to separate control, mild and moderate/severe AD patients have been used in pervious clinical trials (see Wilcock et al., 2008). Total Dementia Rating Scale (DRS) score was also used to classify overall performance as normal or abnormal, using a cut-off score of 123 as recommended by the Mattis Dementia Rating: Professional Manual (Fernandez \& Scheffel, 2003; Green et al., 1995; Jurica et al., 2001; Mattis, 1988). The percentages of individuals exceeding this value for the control, mild and moderate groups were $100 \%, 40 \%$, and $0 \%$, respectively.

Patients in this study met National Institute of Neurological and Communicative Disorders and Stroke-Alzheimer's Disease and Related Disorders Association criteria for probable AD (McKhann et al., 1984), and the Diagnostic and Statistical Manual of Mental Disorders-Fourth Edition (American Psychiatric Association, 1994) criteria for dementia. All patients received a comprehensive clinical evaluation, including detailed medical history, neurological examination, routine laboratory investigation, standardized neuropsychological testing and neuroimaging. Eighty-nine percent of the mild participants and $93 \%$ of the moderate participants were on cholinergic medications. Individuals in this study, not on cholinergic agents were recruited before their clinical availability. Informed consent was obtained from the patients or their substitute decision markers. All procedures and collection of data were in accordance with the Sunnybrook Health Science Centre Research Ethics Board policy.

\section{Neuropsychological Tests}

As discussed above, the Benton Judgement of Line Orientation (BLO) and the Rey-Osterrieth Complex figure (RO) were the cognitive tests used to probe visuoconstructive performance in this study (Benton, 1994; Lezak, 1995). For the BLO, participants were shown 6 practice and 30 test items from the test booklet. Results were scored between 0 and 30. Each item of the test consists of two components: a stimulus on the top page showing 2 lines orientated in a specific configuration, and at the bottom of the page, a semicircular array of 11 possible responses, none of which exceeding $180^{\circ}$. Subjects were required to choose two lines from the array on the bottom page that had the same orientation as the two stimulus lines on the top of the page. Typically, individuals with AD are impaired on this procedure (Eslinger et al., 1985; Eslinger \& Benton, 1983; Ska et al., 1990), usually scoring below the 18-point cutoff (Lezak et al., 2004).

The RO is a well-known instrument used to assess visuoconstructive abilities which requires the copying of a complex geometrical figure and includes a standardized scoring procedure using 18-items and a 36-point scoring system (Corwin \& Bylsma, 1993; Lezak, 1995; Meyers et al., 1996; Spreen \& Strauss, 1998). For this study we decided to use a

Table 1. Demographic characteristic of subjects

\begin{tabular}{|c|c|c|c|c|}
\hline Characteristics & Controls $(N=29)$ & Mild AD $(N=86)$ & Moderate $\mathrm{AD}(N=42)$ & Significance \\
\hline Age, Mean years $\pm S D$ & $70.28 \pm 6.61$ & $69.18 \pm 8.28$ & $68.86 \pm 10.69$ & NSD \\
\hline Male/Female sex, n (\%) & $51 / 49$ & $52 / 48$ & $50 / 50$ & NSD \\
\hline Education, Mean years $\pm S D$ & $15.14 \pm 2.62$ & $13.98 \pm 4.17$ & $13.17 \pm 4.02$ & NSD \\
\hline MMSE Mean $\pm S D$ (Range) & $28.59 \pm .95(27-30)$ & $25.69 \pm 2.30(22-30)$ & $22.34 \pm 6.37(8-21)$ & $\begin{array}{l}\text { All groups: } \\
p<.001\end{array}$ \\
\hline $\begin{array}{l}\text { Disease duration, Mean } \\
\text { months } \pm S D\end{array}$ & $\mathrm{~N} / \mathrm{A}$ & $9.16 \pm 3.42$ & $10.46 \pm 3.83$ & NSD \\
\hline $\begin{array}{l}\text { Dementia Rating Scale (DRS) } \\
\text { Mean } \pm S D \text { (Range) }\end{array}$ & $140.29 \pm 2.7(143-131)$ & $112.81 \pm 17.35(142-68)$ & $97.46 \pm 19.03(126-48)$ & $\begin{array}{l}\text { All groups: } \\
p<.05\end{array}$ \\
\hline
\end{tabular}

Note. Analysis showed no significant differences were observed between participant groups on age, education, and sex. 
23-point cut-off score which is above the normal BLO and RO 31-point cut-off indicating an abnormality to demonstrate even at the upper ends of these procedures considerable differences are apparent.

The DRS comprises a series of five subtests which assess attention, memory, initiation/perseveration, construction, and conceptualization. It can be administered in full in approximately $30 \mathrm{~min}$, and is useful for the detection and estimation of the overall level of dementia (Jurica et al., 2001).

\section{SPECT Scans}

SPECT imaging was performed on the whole brain using a triple-head gamma camera (Prism 3000XP; Phillips Medical Systems Inc, Cleveland, $\mathrm{OH}$ ), a minimum of $30 \mathrm{~min}$ and a maximum of $120 \mathrm{~min}$ after injection of $20 \mathrm{mCi}$ (740 $\mathrm{MBq}$ ) of the radiopharmaceutical Technetium-99m ethyl cysteinate dimer $\left({ }^{99 \mathrm{~m}} \mathrm{Tc}-\mathrm{ECD}\right)$. Each view consisted of a $128 \times 128$ pixel image acquisition matrix with an acquisition zoom of 1.0 and 120 frames were acquired over $360^{\circ}$ (i.e., 60 frames per camera head) in continuous-acquisition mode with a typical reconstructed image resolution of $9.7 \mathrm{~mm}$ full-width at half-maximum (reconstructive field of view $27.6 \mathrm{~cm}$ ). A 120 slices were collected and total imaging time was $19 \mathrm{~min}$. Reconstruction was performed using a ramp-filtered back-projection algorithm followed by a 3-dimensional restoration postfilter (Wiener filter, multiplier 1.0). Ellipses were fit to the approximate location of the outline of the head in each transaxial image and a calculated attenuation correction applied. After attenuation correction voxel size was $2.17 \times 2.17 \times 3.56 \mathrm{~mm}$ and the number of slices ranged from 37 to 57 (Chang, 1978). Reconstructed images were co-registered (AIR) to a region-ofinterest SPECT template, derived by co-registration to a 3D T1-weighted MRI of an elderly control [for a further detailed description of the SPECT protocol, see Lobaugh et al. (2000)]. Mean perfusion in regions of interest (ROI) was referenced to the cerebellum to provide semi-quantitative measures of regional cerebral blood flow (rCBF).

\section{Partial Least Squares (PLS)}

PLS is an analytical method that is useful for understanding the relationships between multiple correlated variables in two domains. PLS is ideal for data sets where the dependent measures within a block are highly correlated (e.g., rCBF values). Behavior PLS is designed to examine brain-behavior correlations. It begins by creating a data matrix containing the mean SPECT ROI values [e.g., columns of imaging data for each patient (128) by the 75 ROIs regions]. This matrix is then cross-correlated with each behavioral measure [e.g., 2 measures (BLO \& RO) for each of the 128 patients]. The product of this cross-correlation analysis creates a set of single vectors for each of the two behavioral measures. These vectors are then stacked into a single matrix and using single decomposition value (SVD) 2 latent variables (LVs) are pro- duced (Number of LVs relate to number of behavioral measures). The LVs allow for the identification of the commonalities and/or differences in brain-behavior relations, and the regions contributing to those effects.

Thus, the PLS multivariate design unlike the univariate design of statistical parametric mapping (SPM) has the ability to provide insight into anatomical "network" connections using two sets of multiple measures (e.g., imaging and behavioral measures). In addition, unlike SPM, PLS has the ability to take into consideration spatiotemporal data as a whole during assessment of brain areas, providing a parsimonious understanding of brain-behavior relationships (Lin et al., 2003).

\section{ANALYSIS}

\section{Neuropsychological Test Analysis}

The first analysis examined the ability of the neuropsychological tests to distinguish among participant groups. Percentage scores were used to demonstrate performance results for the three groups. Groups were examined on all neuropsychological measures using a MANCOVA (multivariate) analysis to examine the main effects and covaried for age, sex, and years of educations. All data were analyzed by the investigators using SPSS for Windows (version 15; SPSS Inc., Chicago, IL).

\section{SPECT Hemispheric Analysis}

First, the main effect of participant groups with respect to regional perfusion ratio were examined using multivariate (Factorial MANCOVA) analysis (values normalized to cerebellum). To examine interaction effects the analysis included covariates for age, education and sex. For this examination the parietal region included five pairs of subregions: PreCuneus, Superior parietal lobe, Supramarginal, Angular Gyrus, and Post Central Gyrus and four temporal regions and one frontal region from each hemisphere: Middle Temporal Gyrus (lateral), Middle Temporal Gyrus (medial), Superior Temporal Gyrus (lateral), Superior Temporal Gyrus (medial), Superior Frontal Gyrus (dorsal) $($ Right $=\mathrm{R}$ and Left $=\mathrm{L}$ ). Regions of interest were defined semi-automatically on SPECT, and were anatomically localized with the aid of co-registered MRI.

A general linear model, ANOVA analysis was also conducted on the normalized means. The role of this analysis was to determine whether there were differences in right and left hemisphere regional perfusion ratios among participant groups. In addition, $t$ test evaluations were used to examine hemispheric bias within the participant populations.

\section{Regression Analysis}

Multiple regression analysis was pursued to elucidate the relationship between parietal perfusion values and the behavioral measures (BLO and RO). Significant values indicate 
that behavioral measures can be effective in understanding perfusion values, however, only to the extent that meaningful data can be retrieved (i.e., stable scores within meaningful range on BLO and RO) from behavioral tasks. This top-down approach was based on the hypothesis that regions within the parietal lobe, particularly on the right would correlate with visuospatial task performance.

\section{PLS Analysis}

A behavioral PLS analysis [available as a Matlab (Mathworks Inc) graphical user interface at http://www.rotmanbaycrest.on.ca/index.php?section $=84]$ was applied to determine the patterns of brain perfusion correlated to performance on the two neuropsychological measures for the patient sample.

Evaluation of the stability of the LVs is done using permutation tests to assess whether the effect represented in a given LV is sufficiently strong, in a statistical sense, to be different from random noise. The significance of the LV is calculated on the value representing the strength of the brain behavior relation (singular value). No corrections for multiple comparisons are necessary because the rCBF saliencies are calculated in a single mathematical step on the whole brain (McIntosh et al., 1996; McIntosh \& Lobaugh, 2004). Bootstrap estimation of standard errors for the ROI saliencies as well as for the correlation of the subjects' "brain scores" (the dot-product of the ROI saliencies with the subject's rCBF data) and neuropsychological data provide measures of the reliability of the obtained results (McIntosh et al., 1996, 2004; Strother et al., 2002).

\section{RESULTS}

\section{Neuropsychological Test Results}

On both the RO and BLO tasks control subjects performed well (becq-Derouesne \& Beauvois, 1989; Spreen \& Strauss, 1998). In fact, for the BLO, $93 \%$ of the control group were above the average cut-off score of 23 . In contrast, $58 \%$ of the mild group were above the cut-off, with an additional $16 \%$ between 21 and 23. In the moderate group, only $10 \%$ were above the cut-off. For the RO, 93\% of the control group were above the cut-off score of 31 , compared with only $36 \%$ of the mild group and $14 \%$ of the moderate group. Performance was significantly impaired on these tasks in both the mild and moderate patient groups (Table 2).

Multivariate analysis (MANCOVA) covarying for age, education, and sex revealed significant differences between all groups on all neuropsychological measures; RO: $F_{2,127}=$ $28.61 ; p<.001$; BLO: $F_{2,127}=27.78 ; p<.001$; and DRS: $F_{2,127}=12.41 ; p<.001$. Covariate factors demonstrated no significant difference between groups $(p<.005)$, but were included because age, education, and sex are known to influence cognitive performance.

\section{SPECT Analysis}

A multivariate (MANCOVA) analysis was conducted, as describe above to compare parietal, temporal, and frontal regional perfusion ratios on the three groups, covarying for age, education, and sex. Main effects between participants groups were observed on the parietal lobe perfusion ratios (Table 3). Covariate analysis displayed no interaction effects (significance level set at $p<.005$ ). Pair-wise comparisons (Bonferroni corrected) displayed a significant difference for all variables at the $p<.005$ level between control participants and AD participants regardless of severity of disease, with the exception of the Postcentral gyrus (bilaterally) (control vs. mild and mild vs. moderate); Superior parietal (left) (mild vs. moderate sample); Supramarginal gyrus (right) (control vs. mild). Main effects between participant groups for temporal and frontal lobe perfusion ratios were also observed (Table 4). Pair-wise comparisons (Bonferroni corrected) of perfusion ratios for temporal and frontal regions showed a differences between control and moderate $\mathrm{AD}$ in the lateral middle temporal gyrus bilateral, and the right lateral superior temporal gyrus.

Table 2. Mean values for two neuropsychological measures: Rey-Osterrieth Figure Copy and Benton Line Orientation, $( \pm)$ represents standard error of the mean

\begin{tabular}{|c|c|c|c|c|}
\hline Neuropsychological Tests & $\begin{array}{c}\text { Controls } \\
N=29\end{array}$ & $\begin{array}{l}\text { AD Patients } \\
\text { (MILD) } \\
N=86\end{array}$ & $\begin{array}{c}\text { AD Patients } \\
\text { (Moderate) } \\
N=42\end{array}$ & Effect Sizes $(d)=$ Cohen's \\
\hline Benton (30-point scale) (Mean/SEM) & $25.46 \pm .69$ & $20.10 \pm .85$ & $10.73 \pm 1.1$ & $\begin{array}{l}\text { control } v s . \text { mild }(\mathrm{d})=.85 \\
\text { mild } v s . \text { moderate }(\mathrm{d})=1.0 \\
\text { control } v s . \text { moderate }(\mathrm{d})=2.0\end{array}$ \\
\hline Rey-Osterrieth (36-point scale) (Mean/SEM) & $33.25 \pm .36$ & $25.53 \pm 1.1$ & $15.95 \pm 1.7$ & $\begin{array}{l}\text { control } v s . \text { mild }(\mathrm{d})=1.0 \\
\text { mild } v s . \text { moderate }(\mathrm{d})=1.1 \\
\text { control } v s . \text { moderate }(\mathrm{d})=2.7\end{array}$ \\
\hline Dementia Rating Scale (Mean/SEM) & $140.29 \pm 2.7$ & $112.81 \pm 1.9$ & $97.46 \pm 3.6$ & $\begin{array}{l}\text { control } v s . \text { mild }(\mathrm{d})=.9 \\
\text { mild } v s . \text { moderate }(\mathrm{d})=2.3 \\
\text { control } v s . \text { moderate }(\mathrm{d})=3.1\end{array}$ \\
\hline
\end{tabular}


Table 3. Results for SPECT ROI analysis among all three participant groups, shown for the specific parietal subregions for each hemisphere, Right (R) and Left (L)

\begin{tabular}{|c|c|c|c|c|}
\hline \multirow{2}{*}{$\frac{\text { ANOVA term (regions) }}{\text { Parietal Lobe }}$} & \multicolumn{3}{|c|}{ Statistic } & \multirow[b]{2}{*}{ Effect sizes } \\
\hline & (df) & $F$ value & $p$ value & \\
\hline Precuneus_L & 2,151 & 22.99 & .000 & $\begin{array}{l}\text { Control vs. mild }(\mathrm{d})=.84 \\
\text { Mild vs. moderate }(\mathrm{d})=.80 \\
\text { Control vs. moderate }(\mathrm{d})=1.8\end{array}$ \\
\hline Precuneus_R & 2,151 & 14.02 & .001 & $\begin{array}{l}\text { Control vs. mild }(\mathrm{d})=1.2 \\
\text { Mild vs. moderate }(\mathrm{d})=.33 \\
\text { Control vs. moderate }(\mathrm{d})=1.6\end{array}$ \\
\hline SupParietal_Lobe_L & 2,151 & 13.70 & .000 & $\begin{array}{l}\text { Control vs. mild }(\mathrm{d})=.86 \\
\text { Mild vs. moderate }(\mathrm{d})=.36 \\
\text { Control vs. moderate }(\mathrm{d})=1.2\end{array}$ \\
\hline SupParietal_Lobe_R & 2,151 & 19.09 & .000 & $\begin{array}{l}\text { Control vs. mild }(\mathrm{d})=.80 \\
\text { Mild vs. moderate }(\mathrm{d})=.80 \\
\text { Control vs. moderate }(\mathrm{d})=1.8\end{array}$ \\
\hline Supramarginal gyrus_L & 2,151 & 21.34 & .000 & $\begin{array}{l}\text { Control vs. mild }(\mathrm{d})=.74 \\
\text { Mild } v s . \text { moderate }(\mathrm{d})=.77 \\
\text { Control } v s . \text { moderate }(\mathrm{d})=1.6\end{array}$ \\
\hline Supramarginal gyrus_R & 2,151 & 12.27 & .000 & $\begin{array}{l}\text { Control vs. mild }(\mathrm{d})=.50 \\
\text { Mild vs. moderate }(\mathrm{d})=.67 \\
\text { Control vs. moderate }(\mathrm{d})=1.2\end{array}$ \\
\hline Angular gyrus_L & 2,151 & 34.15 & .000 & $\begin{array}{l}\text { Control vs. mild }(\mathrm{d})=1.0 \\
\text { Mild } v s . \text { moderate }(\mathrm{d})=1.1 \\
\text { Control vs. moderate }(\mathrm{d})=2.1\end{array}$ \\
\hline Angular gyrus_R & 2,151 & 23.16 & .000 & $\begin{array}{l}\text { Control vs. mild }(\mathrm{d})=1.2 \\
\text { Mild vs. moderate }(\mathrm{d})=.8 \\
\text { Control vs. moderate }(\mathrm{d})=2.0\end{array}$ \\
\hline Postcentral gyrus_L & 2,151 & 3.65 & .028 & $\begin{array}{l}\text { Control vs. mild }(\mathrm{d})=.14 \\
\text { Mild } v s . \text { moderate }(\mathrm{d})=.46 \\
\text { Control } v s . \text { moderate }(\mathrm{d})=.61\end{array}$ \\
\hline Postcentral gyrus_R & 2,151 & 6.42 & .002 & $\begin{array}{l}\text { Control vs. mild }(\mathrm{d})=.36 \\
\text { Mild } v s . \text { moderate }(\mathrm{d})=.57 \\
\text { Control vs. moderate }(\mathrm{d})=.72\end{array}$ \\
\hline
\end{tabular}

Univariate analysis revealed significant group differences for the right and left hemispheres (values normalized to cerebellum) within the parietal lobe; Right: $F_{2,151}=21.18$; $p<.001$; Left: $F_{2,151}=18.12 ; p<.001$. Post hoc analysis showed all groups differed regardless of the severity of $\mathrm{AD}$ or hemisphere $(\mathrm{R} / \mathrm{L})$ Thus, the control group differed significantly from the mild group and the moderate group was significantly different from the mild group: Control vs. Mild $p<.005$, Mild $v s$. Moderate $p<0.001)$. A reduction in regional blood flow (rCBF) was constant within the parietal lobe bilaterally between hemispheres across sample populations (i.e., parallel decreases in hemisphere can be observed) (see Figure 1; Table 5).

\section{Multiple Regression of Perfusion Levels Versus Visuospatial Tasks}

Multiple regressions were performed with normalized means for parietal perfusion ratios and regressed against the BLO and RO. The control population displayed no significant correlation between neuropsychological tests and SPECT data. Within the mild sample, the right superior parietal lobe $\left(F_{1,84}=12.12 ; p<.005 ; R^{2}=.13\right)$ was significantly correlated with the BLO. Similarly the right superior parietal lobe $\left(F_{1,84}=23.20 ; p<.001 ; R^{2}=.22\right)$ and right postcentral gyrus: $F_{1,83}=11.64 ; p<.005 ; R^{2}=.31$, were also significantly correlated with the RO. These results indicate that the mild group had the highest correlations; in moderate patients, floor effects reduced the power to assess these relationships [Very low scores or in some cases no score at all was seen in this subject group (moderate), i.e., zero score $\mathrm{BLO}=17 / 42$; zero score $\mathrm{RO}=2 / 42$ ].

Multiple regressions were performed with normalized means for temporal and frontal perfusion ratios and regressed against the BLO and RO measures. Neither the control group nor the two patients groups displayed significant correlations between neuropsychological tests and these regional perfusion ratios. The absence of significant relationships highlights the specificity of the correlations with the parietal regions. 
Table 4. Results for SPECT ROI analysis among all three participant groups, shown for the specific temporal and frontal subregions for each hemisphere, Right (R) and Left (L)

\begin{tabular}{|c|c|c|c|c|}
\hline \multirow{2}{*}{$\frac{\text { ANOVA term (regions) }}{\text { Parietal Lobe }}$} & \multicolumn{3}{|c|}{ Statistic } & \multirow[b]{2}{*}{ Effect sizes } \\
\hline & (df) & $F$ value & $p$ value & \\
\hline SupFrontalGY_Dors_L & 2,151 & 5.49 & .005 & $\begin{array}{l}\text { Control vs. mild }(\mathrm{d})=.84 \\
\text { Mild } v s . \text { moderate }(\mathrm{d})=.80 \\
\text { Control vs. moderate }(\mathrm{d})=1.8\end{array}$ \\
\hline SupFrontalGY_Dors_R & 2,151 & 5.52 & .005 & $\begin{array}{l}\text { Control vs. mild }(\mathrm{d})=1.2 \\
\text { Mild vs. moderate }(\mathrm{d})=.33 \\
\text { Control vs. moderate }(\mathrm{d})=1.6\end{array}$ \\
\hline MidTempGY_lateral_L & 2,151 & 28.47 & .000 & $\begin{array}{l}\text { Control vs. mild }(\mathrm{d})=.86 \\
\text { Mild vs. moderate }(\mathrm{d})=.36 \\
\text { Control vs. moderate }(\mathrm{d})=1.2\end{array}$ \\
\hline MidTempGY_lateral_R & 2,151 & 24.60 & .000 & $\begin{array}{l}\text { Control vs. mild }(\mathrm{d})=.80 \\
\text { Mild } v s . \text { moderate }(\mathrm{d})=.80 \\
\text { Control vs. moderate }(\mathrm{d})=1.8\end{array}$ \\
\hline MidTempGy_medial_L & 2,151 & 5.94 & .003 & $\begin{array}{l}\text { Control vs. mild }(\mathrm{d})=.74 \\
\text { Mild } v s . \text { moderate }(\mathrm{d})=.77 \\
\text { Control } v s . \text { moderate }(\mathrm{d})=1.6\end{array}$ \\
\hline MidTempGy_medial_R & 2,151 & 5.57 & .005 & $\begin{array}{l}\text { Control } v s . \text { mild }(\mathrm{d})=.50 \\
\text { Mild vs. moderate }(\mathrm{d})=.67 \\
\text { Control vs. moderate }(\mathrm{d})=1.2\end{array}$ \\
\hline SupTempGy_lateral_L & 2,151 & 24.01 & .000 & $\begin{array}{l}\text { Control vs. mild }(\mathrm{d})=1.05 \\
\text { Mild } v s . \text { moderate }(\mathrm{d})=1.1 \\
\text { Control } v s . \text { moderate }(\mathrm{d})=2.2\end{array}$ \\
\hline SupTempGy_lateral_R & 2,151 & 12.45 & .000 & $\begin{array}{l}\text { Control vs. mild }(\mathrm{d})=.92 \\
\text { Mild vs. moderate }(\mathrm{d})=.70 \\
\text { Control vs. moderate }(\mathrm{d})=1.7\end{array}$ \\
\hline SupTempGy_medial_L & 2,151 & 5.19 & .007 & $\begin{array}{l}\text { Control vs. mild }(\mathrm{d})=.45 \\
\text { Mild vs. moderate }(\mathrm{d})=.27 \\
\text { Control vs. moderate }(\mathrm{d})=.67\end{array}$ \\
\hline SupTempGy_medial_R & 2,151 & 2.88 & .059 & $\begin{array}{l}\text { Control vs. mild }(\mathrm{d})=.33 \\
\text { Mild } v s . \text { moderate }(\mathrm{d})=.39 \\
\text { Control vs. moderate }(\mathrm{d})=.65\end{array}$ \\
\hline
\end{tabular}

\section{PLS Results}

PLS analysis was undertaken between all brain regions and behavioral performance on BLO and RO for our patient populations. Two latent variables were produced by this analysis (1000 permutations/500 bootstraps; see McIntosh et al., 2004), but only the first (BLO) was found to be significant. A singular image was produced which reflected the regions contributing to the brain behavior relationship. Ratios that were greater than 2.58 (a $Z$-score equivalent of a .003 level of significance) were considered stable (Figure 2). It is important to note that no single region can produce these results, but rather it is the pattern of identified network regions that contributed to observed behavioral differences. Strong stable negative salience regions were: [Parietal lobe (left), Medial Temporal Gyrus (left lateral), Superior Temporal Gyrus (left lateral), Super Marginal Gyrus (right anterior), Inferior Frontal Gyrus (left medial), Postcentral Gyrus (left), Lingual Gyrus (bilateral), Middle frontal gyrus posterior (bilateral), Paracentral (anterior) bilateral, Insula (left), Obitial frontal gyrus (right),
Cingulate anterior (right ventral), RetroSplen (left), Posterior Cingulate, Caudate Putamen, Thalamus (right)]. These patterns (dark regions) are summarized in a schematic depiction of the brain template (Figure 2). These results indicate that the patients have a large number of negatively salient brain areas in relation to behavioral tasks. Thus, lower scores, particularly on the BLO, reflected reduced perfusion ratios.

\section{DISCUSSION}

This study was designed to elucidate brain-behavior correlations between visual constructive and visual spatial neuropsychological tasks and regional brain perfusion ratios. The parietal region has been implicated as an area essential for spatial attention/orientation, as well as a region mediating visuoconstructive spatial tasks such as BLO and RO. Rightside decrease in perfusion was associated with worse performance on the BLO and the RO tests, as expected. The PLS analysis displayed a complex network of connections (e.g., multitude of brain regions), linking other brain regions such as the frontal lobe mediating executive aspects of the 


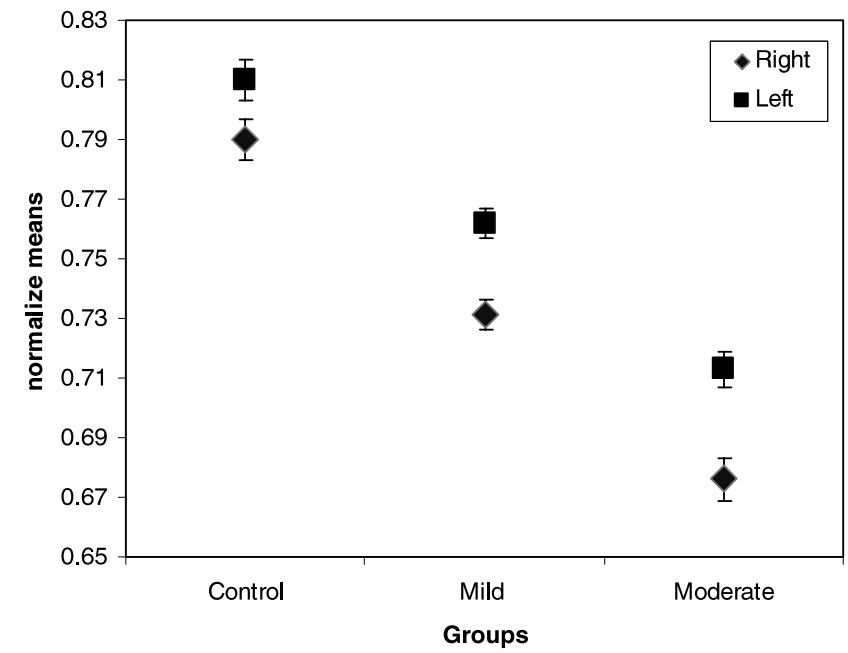

SPECT PERFUSION RATIO'S PARIETAL L/R

Fig. 1. Displayed are the SPECT (rCBF) ratios within the parietal regions for both the right and left hemisphere, for Control, probable Mild and Moderate AD, error bars represent standard error of the mean. Whole hemisphere analyses indicated that all groups differed significantly at $p<.001$ level. As well, within each group the left versus right hemisphere was significantly different at the $p<.001$.

RO procedure, although a key processing area remained the parietal lobe, and, as shown, the strongest salient relationship remained the "purer" visuospatial procedure of the BLO, with minimal motor demands.

\section{Neuropsychological Test and SPECT Results}

Typically, lesion studies with BLO have demonstrated that individuals with right parietal lobe damage, specifically, the superior parietal lobe, are more impaired on task completion than individuals with left parietal lobe damage (Benton, 1994; Benton et al., 1978; Hamsher et al., 1992; Nobili et al., 2005). More recently, researchers have suggested that

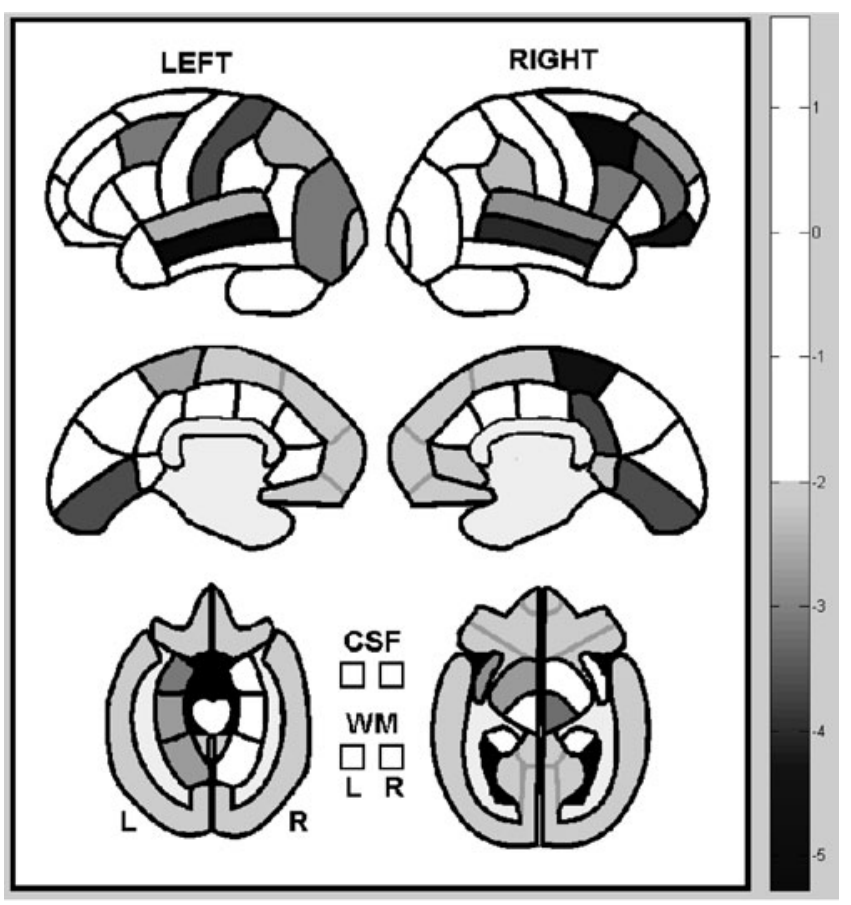

Fig. 2. PLS map of network regions showing the groups SPECT perfusion patterns, in relation to the BLO and RO behavior measures. Scales shows Brain Scores (obtain via PLS) and reflects overall weight variable throughout 75 ROI regions. White regions indicate areas with no relationship. Gray areas indicate a mild relationship to behavioral tasks. Black areas indicate a strong relationship to behavioral tasks.

both hemispheres are in fact important for BLO completion (Brown \& Kosslyn, 1993; Corbetta et al., 1993; Martinez et al., 1997) with relatively more activation from the right superior parietal hemisphere ( $\mathrm{Ng}$ et al., 2000). Interestingly, in this study the mild subgroup showed significant relationships on both the BLO and RO to the superior parietal lobe (right), but this was no longer apparent in the moderate stage of the disease. This could be attributed to the inability to retrieve meaningful data due significant per-

Table 5. SPECT perfusion values for all three participant groups, shown for the specific parietal subregions for each hemisphere, Right (R) and Left (L)

\begin{tabular}{lccc}
\hline \hline $\begin{array}{l}\text { Parietal lobe } \\
\text { Perfusion ratio values (rCBF) }\end{array}$ & $\begin{array}{c}\text { Control } \\
\text { Means and standard deviation }\end{array}$ & $\begin{array}{c}\text { Mild } \\
\text { Means and standard deviation }\end{array}$ & $\begin{array}{c}\text { Moderate } \\
\text { Means and standard deviation }\end{array}$ \\
\hline Precuneus_L & $.922 \pm .01$ & $.856 \pm .01$ & $.797 \pm .01$ \\
Precuneus_R & $.892 \pm .01$ & $.823 \pm .01$ & $.768 \pm .01$ \\
SupParietal_Lobe_L & $.719 \pm .01$ & $.664 \pm .01$ & $.627 \pm .01$ \\
SupParietal_Lobe_R & $.732 \pm .01$ & $.670 \pm .01$ & $.613 \pm .01$ \\
Supramarginal gyrus_L & $.80 \pm .01$ & $.734 \pm .01$ & $.672 \pm .01$ \\
Supramarginal gyrus_R & $.764 \pm .01$ & $.724 \pm .01$ & $.667 \pm .01$ \\
Angulargyrus_L & $.861 \pm .01$ & $.779 \pm .01$ & $.685 \pm .02$ \\
Angular gyrus_R & $.843 \pm .01$ & $.765 \pm .01$ & $.688 \pm .02$ \\
Postcentral gyrus_L & $.802 \pm .01$ & $.770 \pm .00$ & $.751 \pm .01$ \\
Postcentral gyrus_R & $.720 \pm .00$ & $.697 \pm .00$ & $.672 \pm .00$ \\
\hline \hline
\end{tabular}


formance deficits in the moderate group (i.e., low ranges of performance and the inability to pass screening procedures and generate meaningful data).

SPECT analysis demonstrated that significant differences in perfusion ratios substantial hypoperfusion can be observed bilaterally between $\mathrm{AD}$ and controls in parietal ROIs. In addition, more parietal regions differed significantly between participant groups compared with temporal and frontal regions. Confirming the sensitivity of resting state imaging measures, identified to be affected early in AD (Houston et al., 1998; Johnson et al., 2005).

Thus, visuomotor tasks may provide an additional measure of decline, particularly, in individuals with high premorbid verbal ability (e.g., high cognitive reserve) (Scarmeas \& Stern, 2004; Stern, 2006) .

\section{Multiple Regressions}

The multiple regression analysis suggests that in $A D$, significant relationships can be observed between the visuospatial tasks and the parietal ROIs. Specifically, hypoperfused parietal regions may be related to reductions observed in task performance, particularly in mild $\mathrm{AD}$, giving validation to these visuospatial tasks as cognitive measures with regional neural correlates in AD. These results support the potential utility of tasks probing visuospatial ability to detect the presence of and track the course of AD.

\section{Partial Least Squares Analysis}

It is important to remember that entire networks of brain regions are involved in completing even the simplest of tasks. PLS analysis is an innovative method with which to examine brain values ( $\mathrm{rCBF}$ ) in relation to behavioral measures. It uses data from the entire brain to determine the network of regions may be contributing to task performance. In this sample, the BLO was the only measure to show a stable relationship, suggesting that reduced performance on this behavioral measure was related to decreased perfusion ratios in the parietal regions.

\section{CONCLUSION}

This study used both bottom-up and top-down analyses to examine brain behavior relationships in the visual-spatial domain in $\mathrm{AD}$ compared with age-matched controls. The large sample size and the range of severity included demonstrated that parietal hypoperfusion correlated with poorer visuospatial performance, and was identifiable even in mild stage $\mathrm{AD}$, suggesting that this cognitive domain can be a useful probe of cognitive decline in mild AD, which could be particularly helpful in patients whose verbal abilities are relatively preserved.

\section{ACKNOWLEDGMENTS}

The authors thank Dr. Nancy Lobaugh and Farrell Leibovitch for assistance in interpreting the PLS analysis and to acknowledge the assistance of the following individuals, who administered the cognitive tests: Jennifer Bray, Brain Buck, Patricia Ebert, Carly Guberman, Stephen Kohler, Le-Anh Ngo, Christine Pond, and Amber Vance. A special thanks to Naama Levy-Cooperman and Isabel Lam for their assistance with the SPECT database. This research was supported by Canadian Institute of Health Research (MT13129) as well as Alzheimer's Society of Canada, Alzheimer's Association US and the LC Campbell Cognitive Neurology Unit.

\section{REFERENCES}

Alexander, G.E., Chen, K., Pietrini, P., Rapoport, S.I., \& Reiman, E.M. (2002). Longitudinal PET evaluation of cerebral metabolic decline in dementia: A potential outcome measure in Alzheimer's disease treatment studies. American Journal of Psychiatry, 159, 738-745.

American Psychiatric Association. (1994). Diagnostic and Statistical Manual of Mental Disorders (4th ed.). Washington DC: American Psychiatric Association.

Andersen, R.A. \& Buneo, C.A. (2003). Sensorimotor integration in posterior parietal cortex. Advances in Neurology, 93, 159-177.

Arbizu, J., Larumbe, R., Gamez, C., Marti, J., Martinez-Lage, J., \& Richter, J. (1999). [Correlations between brain SPECT and neuropsychology assessments in mild and moderate stages of Alzheimer's disease]. Revista Espanola de Medicina Nuclear, 18, 252-260.

Bartenstein, P., Minoshima, S., Hirsch, C., Buch, K., Willoch, F., Mosch, D., Schad, D., Schwaiger, M., \& Kurz, A. (1997). Quantitative assessment of cerebral blood flow in patients with Alzheimer's disease by SPECT. Journal of Nuclear Medicine, 38 , 1095-1101.

becq-Derouesne, J. \& Beauvois, M.F. (1989). Memory processes and aging: A defect of automatic rather than controlled processes? Archives of Gerontology and Geriatrics, 1, 121-150.

Beebe, D.W., Ris, M.D., Brown, T.M., \& Dietrich, K.N. (2004). Executive functioning and memory for the Rey-Osterreith complex figure task among community adolescents. Applied Neuropsychology, 11, 91-98.

Benton, A.L. (1994). Neuropsychological assessment. Annual Review of Psychology, 45, 1-23.

Benton, A.L., Varney, N.R., \& Hamsher, K.S. (1978). Lateral differences in tactile directional perception. Neuropsychologia, 16, 109-114.

Bisiach, E., Vallar, G., Perani, D., Papagno, C., \& Berti, A. (1986). Unawareness of disease following lesions of the right hemisphere: Anosognosia for hemiplegia and anosognosia for hemianopia. Neuropsychologia, 24, 471-482.

Bonte, F.J., Harris, T.S., Roney, C.A., \& Hynan, L.S. (2004). Differential diagnosis between Alzheimer's and frontotemporal disease by the posterior cingulate sign. Journal of Nuclear Medicine, 45, 771-774.

Boxer, A.L., Kramer, J.H., Du, A.T., Schuff, N., Weiner, M.W., Miller, B.L., \& Rosen, H.J. (2003a). Focal right inferotemporal atrophy in $\mathrm{AD}$ with disproportionate visual constructive impairment. Neurology, 61, 1485-1491.

Boxer, A.L., Rankin, K.P., Miller, B.L., Schuff, N., Weiner, M., Gorno-Tempini, M.L., \& Rosen, H.J. (2003b). Cinguloparietal atrophy distinguishes Alzheimer disease from semantic dementia. Archives of Neurology, 60, 949-956.

Braak, H. \& Braak, E. (1991). Neuropathological staging of Alzheimer-related changes. Acta Neuropathologica, 82, 239-259. 
Brown, H.D. \& Kosslyn, S.M. (1993). Cerebral lateralization. Current Opinion in Neurobiology, 3, 183-186.

Buchert, R., Wilke, F., Chakrabarti, B., Martin, B., Brenner, W., Mester, J., \& Clausen, M. (2005). Adjusted scaling of FDG positron emission tomography images for statistical evaluation in patients with suspected Alzheimer's disease. Journal of Neuroimaging, 15, 348-355.

Buck, B.H., Black, S.E., Behrmann, M., Caldwell, C., \& Bronskill, M.J. (1997). Spatial- and object-based attentional deficits in Alzheimer's disease. Relationship to HMPAO-SPECT measures of parietal perfusion. Brain, 120(Pt 7), 1229-1244.

Buneo, C.A. \& Andersen, R.A. (2006). The posterior parietal cortex: Sensorimotor interface for the planning and online control of visually guided movements. Neuropsychologia, 44, 2594 2606

Buneo, C.A., Jarvis, M.R., Batista, A.P., \& Andersen, R.A. (2002). Direct visuomotor transformations for reaching. Nature, 416, 632-636.

Chang, L.T. (1978). A method for attenuation correction in radionuclide computed tomography. IEEE Transactions on Nuclear Science, 25, 638-643.

Chung, P.K., Jeong, Y., Hwa, L.B., Kim, E.J., Moon, K.G., Heilman, K.M., \& Na, D.L. (2005). Left hemispatial visual neglect associated with a combined right occipital and splenial lesion: Another disconnection syndrome. Neurocase, 11, 310-318.

Corbetta, M., Miezin, F.M., Shulman, G.L., \& Petersen, S.E. (1993). A PET study of visuospatial attention. Journal of Neuroscience, 13, 1202-1226.

Corwin, J. \& Bylsma, F.W. (1993). Psychological examination of traumatic encephalopathy. The Clinical Neuropsychologist, 7 , $3-21$.

Cutler, N.R. (1988). Cognitive and brain imaging measures of Alzheimer's disease. Neurobiology of Aging, 9, 90-92.

Desgranges, B., Baron, J.C., de la Sayette, V., Petit-Taboue, M.C., Benali, K., Landeau, B., Lechevalier, B., \& Eustache, F. (1998). The neural substrates of memory systems impairment in Alzheimer's disease. A PET study of resting brain glucose utilization. Brain, 121(Pt 4), 611-631.

Duhamel, J.R., Colby, C.L., \& Goldberg, M.E. (1992). The updating of the representation of visual space in parietal cortex by intended eye movements. Science, 255, 90-92.

Elble, R.J. \& Leffler, K. (2000). Pushing and pulling with the upper extremities while standing: The effects of mild Alzheimer dementia and Parkinson's disease. Movement Disorders, $15,255-268$.

Elgh, E., Sundstrom, T., Nasman, B., Ahlstrom, R., \& Nyberg, L. (2002). Memory functions and $\mathrm{rCBF}(99 \mathrm{~m}) \mathrm{Tc}-\mathrm{HMPAO}$ SPET: Developing diagnostics in Alzheimer's disease. European Journal of Nuclear Medicine and Molecular Imaging, 29, 11401148 .

Eslinger, P.J. \& Benton, A.L. (1983). Visuoperceptual performances in aging and dementia: Clinical and theoretical implications. Journal of Clinical Neuropsychology, 5, 213-220.

Eslinger, P.J., Damasio, A.R., Benton, A.L., \& Van, A.M. (1985). Neuropsychologic detection of abnormal mental decline in older persons. The Journal of the American Medical Association, 253, 670-674.

Fernandez, A.L. \& Scheffel, D.L. (2003). A study of the criterion validity of the Mattis Dementia Rating Scale. International Journal of Testing, 3, 49-58.

Foster, N.L., Chase, T.N., Fedio, P., Patronas, N.J., Brooks, R.A., \& Di Chiro, G. (1983). Alzheimer's disease: Focal cortical changes shown by positron emission tomography. Neurology, 33, 961-965.

Foster, N.L., Chase, T.N., Mansi, L., Brooks, R., Fedio, P., Patronas, N.J., \& Di Chiro, G. (1984). Cortical abnormalities in Alzheimer's disease. Annals of Neurology, 16, 649-654.

Fujimori, M., Imamura, T., Yamashita, H., Hirono, N., Ikejiri, Y., Shimomura, T., \& Mori, E. (1998). Age at onset and visuocognitive disturbances in Alzheimer disease. Alzheimer Disease and Associated Disorders, 12, 163-166.

Ghilardi, M.F., Alberoni, M., Marelli, S., Rossi, M., Franceschi, M., Ghez, C., \& Fazio, F. (1999). Impaired movement control in Alzheimer's disease. Neuroscience Letters, 260, 45-48.

Goodale, M.A. (1993). Visual pathways supporting perception and action in the primate cerebral cortex. Current Opinion in Neurobiology, 3, 578-585.

Grea, H., Pisella, L., Rossetti, Y., Desmurget, M., Tilikete, C., Grafton, S., Prablanc, C., \& Vighetto, A. (2002). A lesion of the posterior parietal cortex disrupts on-line adjustments during aiming movements. Neuropsychologia, 40, 2471-2480.

Green, R.C., Woodard, J.L., \& Green, J. (1995). Validity of the Mattis Dementia Rating Scale for detection of cognitive impairment in the elderly. The Journal of Neuropsychiatry and Clinical Neurosciences, 7, 357-360.

Hamsher, K., Capruso, D.X., \& Benton, A. (1992). Visuospatial judgment and right hemisphere disease. Cortex, 28, 493-495.

Hannay, H.J., Falgout, J.C., Leli, D.A., Katholi, C.R., Halsey, J.H., Jr., \& Wills, E.L. (1987). Focal right temporo-occipital blood flow changes associated with judgment of line orientation. Neuropsychologia, 25, 755-763.

Herrmann, M.J., Ehlis, A.C., Wagener, A., Jacob, C.P., \& Fallgatter, A.J. (2005). Near-infrared optical topography to assess activation of the parietal cortex during a visuo-spatial task. Neuropsychologia, 43, 1713-1720.

Hirao, K., Ohnishi, T., Hirata, Y., Yamashita, F., Mori, T., Moriguchi, Y., Matsuda, H., Nemoto, K., Imabayashi, E., Yamada, M., Iwamoto, T., Arima, K., \& Asada, T. (2005). The prediction of rapid conversion to Alzheimer's disease in mild cognitive impairment using regional cerebral blood flow SPECT. Neuroimage, 28, 1014-1021.

Houston, A.S., Kemp, P.M., Macleod, M.A., Francis, J.R., Colohan, H.A., \& Matthews, H.P. (1998). Use of significance image to determine patterns of cortical blood flow abnormality in pathological and at-risk groups. Journal of Nuclear Medicine, 39, 425-430.

Ishii, K., Kono, A.K., Sasaki, H., Miyamoto, N., Fukuda, T., Sakamoto, S., Sakamoto, S., \& Mori, E. (2006). Fully automatic diagnostic system for early- and late-onset mild Alzheimer's disease using FDG PET and 3D-SSP. European Journal of Nuclear Medicine and Molecular Imaging, 33, 575-583.

Jagust, W.J., Eberling, J.L., Reed, B.R., Mathis, C.A., \& Budinger, T.F. (1997). Clinical studies of cerebral blood flow in Alzheimer's disease. Annals of the New York Academy of Sciences, $826,254-262$.

Johnson, N.A., Jahng, G.H., Weiner, M.W., Miller, B.L., Chui, H.C., Jagust, W.J., Sakamoto, S., \& Mori, E. (2005). Pattern of cerebral hypoperfusion in Alzheimer disease and mild cognitive impairment measured with arterial spin-labeling MR imaging: Initial experience. Radiology, 234, 851-859.

Jurica, P.J., Leitten, C.L., \& Mattis, S. (2001). Dementia Rating Scale-2. Archives of Clinical Neuropsychology, 19, 145-147.

Kang, D.H., Kwon, J.S., Kim, J.J., Youn, T., Park, H.J., Kim, M.S., Lee, D.S., \& Lee, M.C. (2003). Brain glucose metabolic changes 
associated with neuropsychological improvements after 4 months of treatment in patients with obsessive-compulsive disorder. Acta Psychiatrica Scandinavica, 107, 291-297.

Kasai, M., Meguro, K., Hashimoto, R., Ishizaki, J., Yamadori, A., \& Mori, E. (2006). Non-verbal learning is impaired in very mild Alzheimer's disease (CDR 0.5): Normative data from the learning version of the Rey-Osterrieth Complex Figure Test. Psychiatry and Clinical Neurosciences, 60, 139-146.

Kluger, A., Gianutsos, J.G., Golomb, J., Ferris, S.H., George, A.E., Franssen, E., \& Reisberg, B. (1997). Patterns of motor impairement in normal aging, mild cognitive decline, and early Alzheimer's disease. The Journals of Gerontology. Series B, Psychological Sciences and Social Science, 52, 28-39.

Kogure, D., Matsuda, H., Ohnishi, T., Asada, T., Uno, M., Kunihiro, T., Nakano, S., \& Takasaki, M. (2000). Longitudinal evaluation of early Alzheimer's disease using brain perfusion SPECT. Journal of Nuclear Medicine, 41, 1155-1162.

Kolb, B. \& Wishaw, I.Q. (1996). Fundamentals of Human Neuropsychology (4th ed.) New York: Freeman and Company.

Lampl, Y., Sadeh, M., Laker, O., \& Lorberboym, M. (2003). Correlation of neuropsychological evaluation and SPECT imaging in patients with Alzheimer's disease. International Journal of Geriatric Psychiatry, 18, 288-291.

Larumbe, R. (1997). [Detection of early cases of Alzheimer's disease. Application of the CERAD neuropsychological test battery]. Revista de Medicina de la Universidad de Navarra, 41, 6-11.

Levin, H.S. \& Benton, A.L. (1976). Proprioceptive feedback performance in patients with focal brain lesions. Journal of Neurology, 212, 117-121.

Lezak, M.D. (1995). Neuropsychological Assessment (3rd ed.). New York: Oxford University Press.

Lezak, M.D., Howieson, D.B., \& Loring, D.W. (2004). Neuropsychological Assessment (4th ed.). New York: Oxford University Press.

Lin, F.H., McIntosh, A.R., Agnew, J.A., Eden, G.F., Zeffiro, T.A., \& Belliveau, J.W. (2003). Multivariate analysis of neuronal interactions in the generalized partial least squares framework: Simulations and empirical studies. Neuroimage, 20, 625-642.

Lobaugh, N.J., Caldwell, C.B., Black, S.E., Leibovitch, F.S., \& Swartz, R.H. (2000). Three brain SPECT region-of-interest templates in elderly people: Normative values, hemispheric asymmetries, and a comparison of single- and multihead cameras. Journal of Nuclear Medicine, 41, 45-56.

Loewenstein, D.A., Acevedo, A., Ownby, R., Agron, J., Barker, W.W., Isaacson, R., Isaacson, R., Strauman, S., \& Duara, R. (2006). Using different memory cutoffs to assess mild cognitive impairment. American Journal of Geriatric Psychiatry, 14, 911-919.

Mandzia, J., Black, S., Grady, C., McAndrews, M.P., \& Graham, S. (2002). Encoding and retrieval in aging and memory loss, a fMRI study. Brain and Cognition, 49, 225-228.

Martinez, A., Moses, P., Frank, L., Buxton, R., Wong, E., \& Stiles, J. (1997). Hemispheric asymmetries in global and local processing: Evidence from fMRI. Neuroreport, 8, 1685-1689.

Matsuda, H., Kitayama, N., Ohnishi, T., Asada, T., Nakano, S., Sakamoto, S., Imabayashi, E., \& Katoh, A. (2002). Longitudinal evaluation of both morphologic and functional changes in the same individuals with Alzheimer's disease. Journal of Nuclear Medicine, 43, 304-311.

Mattis, S. (1988). Dementia Rating Scale: Professional Manual. Odessa, FL: Psychological Assessment Resources Inc.
McGeer, P.L., Kamo, H., Harrop, R., McGeer, E.G., Martin, W.R., Pate, B.D., \& Li, D.K. (1986). Comparison of PET, MRI, and CT with pathology in a proven case of Alzheimer's disease. Neurology, 36, 1569-1574.

McIntosh, A.R., Bookstein, F.L., Haxby, J.V., \& Grady, C.L. (1996). Spatial pattern analysis of functional brain images using partial least squares. Neuroimage, 3, 143-157.

McIntosh, A.R., Chau, W.K., \& Protzner, A.B. (2004). Spatiotemporal analysis of event-related fMRI data using partial least squares. Neuroimage, 23, 764-775.

McIntosh, A.R. \& Lobaugh, N.J. (2004). Partial least squares analysis of neuroimaging data: Applications and advances. Neuroimage, 23(Suppl. 1), S250-S263.

McKhann, G., Drachman, D., Folstein, M., Katzman, R., Price, D., \& Stadlan, E.M. (1984). Clinical diagnosis of Alzheimer's disease: Report of the NINCDS-ADRDA Work Group under the auspices of Department of Health and Human Services Task Force on Alzheimer's Disease. Neurology, 34, 939944.

Meguro, K., Shimada, M., Someya, K., Horikawa, A., \& Yamadori, A. (2001). Hemispatial visual-searching impairment correlated with decreased contralateral parietal blood flow in Alzheimer disease. Neuropsychiatry, Neuropsychology, and Behavioral Neurology, 14, 213-218.

Meyers, J.E., Bayless, J.D., \& Meyers, K.R. (1996). Rey complex figure: Memory error patterns and functional abilities. Applied Neuropsychology, 3, 89-92.

Mito, Y., Yoshida, K., Yabe, I., Makino, K., Hirotani, M., Tashiro, K., Kikuchi, S., \& Sasaki, H. (2005). Brain 3D-SSP SPECT analysis in dementia with Lewy bodies, Parkinson's disease with and without dementia, and Alzheimer's disease. Clinical Neurology and Neurosurgery, 107, 396-403.

Mohs, R.C. \& Cohen, L. (1988). Alzheimer's Disease Assessment Scale (ADAS). Psychopharmacology Bulletin, 24, 627-628.

Moren, M.G., Davis, A.S., Brinkman, J.J., \& Dean, R.S. (2005). Neuropsychological measures and single photon emission computed tomography in the differentiation and classification of cerebral perfusion deficits in Alzheimer's dementia. International Journal of Neuroscience, 115, 1131-1149.

Nagahama, Y., Nabatame, H., Okina, T., Yamauchi, H., Narita, M., Fujimoto, N., Murakami, M., Fukuyama, H., \& Matsuda, M. (2003). Cerebral correlates of the progression rate of the cognitive decline in probable Alzheimer's disease. European Neurology, 50, 1-9.

Ng, V.W., Eslinger, P.J., Williams, S.C., Brammer, M.J., Bullmore, E.T., Andrew, C.M., Suckling, J., Morris, R.G., \& Benton, A.L. (2000). Hemispheric preference in visuospatial processing: A complementary approach with fMRI and lesion studies. Human Brain Mapping, 10, 80-86.

Nobili, F., Brugnolo, A., Calvini, P., Copello, F., De Leo, C., Girtler, N., Morbelli, S., Piccardo, A., Vitali, P., \& Rodriguez, G. (2005). Resting SPECT-neuropsychology correlation in very mild Alzheimer's disease. Clinical Neurophysiology, 116, 364-375.

Nobili, F., Vitali, P., Calvini, P., Bollati, F., Girtler, N., Delmonte, M., Mariani, G., \& Rodriguez, G. (2001). Clinical correlative evaluation of an iterative method for reconstruction of brain SPECT images. Nuclear Medicine and Biology, 28, 627-632.

Ott, B.R., Ellias, S.A., \& Lannon, M.C. (1995). Quantitative assessment of movement in Alzheimer's disease. Journal of Geriatric Psychiatry and Neurology, 8, 71-75.

Oyachi, H. \& Ohtsuka, K. (1995). Transcranial magnetic stimulation of the posterior parietal cortex degrades accuracy of 
memory-guided saccades in humans. Investigative Ophthalmology \& Visual Science, 36, 1441-1449.

Prvulovic, D., Hubl, D., Sack, A.T., Melillo, L., Maurer, K., Frolich, L., Lanfermann, H., Zanella, F.E., Goebel, R., Linden, D.E., \& Dierks, T. (2002). Functional imaging of visuospatial processing in Alzheimer's disease. Neuroimage, 17, 1403-1414.

Rodriguez, G., Morbelli, S., Brugnolo, A., Calvini, P., Girtler, N., Piccardo, A., Dougall, N.J., Ebmeier, K.P., Baron, J.C., \& Nobili, F. (2005). Global cognitive impairment should be taken into account in SPECT-neuropsychology correlations: The example of verbal memory in very mild Alzheimer's disease. European Journal of Nuclear Medicine and Molecular Imaging, 32, 1186-1192.

Salmon, E., Lekeu, F., Bastin, C., Garraux, G., \& Collette, F. (2008). Functional imaging of cognition in Alzheimer's disease using positron emission tomography. Neuropsychologia, 46, 1613-1623.

Scarmeas, N. \& Stern, Y. (2004). Cognitive reserve: Implications for diagnosis and prevention of Alzheimer's disease. Current Neurology and Neuroscience Reports, 4, 374-380.

Silverman, D.H. (2004). Brain 18F-FDG PET in the diagnosis of neurodegenerative dementias: Comparison with perfusion SPECT and with clinical evaluations lacking nuclear imaging. Journal of Nuclear Medicine, 45, 594-607.

Silverman, D.H., Small, G.W., Chang, C.Y., Lu, C.S., Kung De Aburto, M.A., Chen, W., Czernin, J., Rapoport, S.I., Pietrini, P., Alexander, G.E., Schapiro, M.B., Jagust, W.J., Hoffman, J.M., Welsh-Bohmer, K.A., Alavi, A., Clark, C.M., Salmon, E., de Leon, M.J., Mielke, R., Cummings, J.L., Kowell, A.P., Gambhir, S.S., Hoh, C.K., \& Phelps, M.E. (2001). Positron emission tomography in evaluation of dementia: Regional brain metabolism and long-term outcome. The Journal of the American Medical Association, 286, 2120-2127.

Ska, B., Poissant, A., \& Joanette, Y. (1990). Line orientation judgment in normal elderly and subjects with dementia of Alzheimer's type. Journal of Clinical and Experimental Neuropsychology, 12, 695-702.

Snyder, L.H., Batista, A.P., \& Andersen, R.A. (1997). Coding of intention in the posterior parietal cortex. Nature, 386, 167-170.

Sowell, E.R., Delis, D., Stiles, J., \& Jernigan, T.L. (2001). Improved memory functioning and frontal lobe maturation between childhood and adolescence: A structural MRI study. Journal of the International Neuropsychological Society, 7, 312-322.

Spreen, O. \& Strauss, E. (1998). A Compendium of Neuropsychological Tests (2nd ed.). New York: Oxford Univeristy Press.
Starkstein, S.E., Sabe, L., Vazquez, S., Teson, A., Petracca, G., Chemerinski, E., Di Lorenzo, G., \& Leiguarda, R. (1996). Neuropsychological, psychiatric, and cerebral blood flow findings in vascular dementia and Alzheimer's disease. Stroke, 27, 408-414.

Stern, B. \& Stern, J.M. (1985). The Rey-Osterrieth Complex as a diagnostic measure of neuropsychological outcome of brain injury. Scandinavian Journal of Rehabilitation Medicine. Supplement, 12, 31-35.

Stern, Y. (2006). Cognitive reserve and Alzheimer disease. Alzheimer Disease and Associated Disorders, 20, S69-S74.

Strother, S.C., Anderson, J., Hansen, L.K., Kjems, U., Kustra, R., Sidtis, J., Frutiger, S., Muley, S., LaConte, S., \& Rottenberg, D. (2002). The quantitative evaluation of functional neuroimaging experiments: The NPAIRS data analysis framework. Neuroimage, 15, 747-771.

Tei, H., Miyazaki, A., Iwata, M., Osawa, M., Nagata, Y., \& Maruyama, S. (1997). Early-stage Alzheimer's disease and multiple subcortical infarction with mild cognitive impairment: neuropsychological comparison using an easily applicable test battery. Dementia and Geriatric Cognitive Disorders, 8, 355-358.

Temple, R.O., Davis, J.D., Silverman, I., \& Tremont, G. (2006). Differential impact of executive function on visual memory tasks. The Clinical Neuropsychologist, 20, 480-490.

Tippett, W.J. \& Sergio, L.E. (2006). Visuomotor integration is impaired in early stage Alzheimer's disease. Brain Research, 1102, 92-102.

von Broczyskowski, D., Wilke, F., Martin, B., Brenner, W., Clausen, M., Mester, J., \& Buchert, R. (2006). Evaluation of a new expert system for fully automated detection of the Alzheimer's dementia pattern in FDG PET. Nuclear Medicine Communications, 27, 739-743.

Watanabe, K., Ogino, T., Nakano, K., Hattori, J., Kado, Y., Sanada, S., \& Ohtsuka, Y. (2005). The Rey-Osterrieth Complex Figure as a measure of executive function in childhood. Brain and Development, 27, 564-569.

Wilcock, G.K., Black, S.E., Hendrix, S.B., Zavitz, K.H., Swabb, E.A., \& Laughlin, M.A. (2008). Efficacy and safety of tarenflurbil in mild to moderate Alzheimer's disease: A randomised phase II trial. Lancet Neurology, 7, 483-493.

Yamaguchi, S., Meguro, K., Itoh, M., Hayasaka, C., Shimada, M., Yamazaki, H., \& Yamadori, A. (1997). Decreased cortical glucose metabolism correlates with hippocampal atrophy in Alzheimer's disease as shown by MRI and PET. Journal of Neurology, Neurosurgery, and Psychiatry, 62, 596-600. 